\title{
Formation Mechanism of a Wide-Face Longitudinal Off-Corner Depression During Thick Slab Continuous Casting
}

\author{
ZHENYU NIU, ZHAOZHEN CAI, and MIAOYONG ZHU
}

In practical continuous casting, consecutive longitudinal depressions often occur in the off-corner areas of slab wide faces, which may cause surface cracks in the depression areas and subsurface cracks beneath the depressions. To investigate the formation mechanism of the longitudinal depression, a 3D transient thermomechanical-coupled model was developed in the present work with consideration of the heat transfer in steel strand, thermal shrinkage of solidifying shell, ferrostatic pressure, contact with mold and guiding rolls, etc. Based on the model, evolution of the longitudinal off-corner depression and the associated thermal, distortion, and strain behaviors of steel slab were studied partly or fully throughout the continuous casting process. The results showed that the shell shrinkage in mold leads to an obvious shell-mold interfacial gap in the corner and off-corner areas. At the mold exit, the continuous expansion of corner gap at the wide-face side results in a thin spot forming at approximately $50 \mathrm{~mm}$ off the corner. When the shell moves out of the lateral strand guide rolls, narrow face of the shell bulges outward and rotates the corner, during which the thin spot in the wide-face off-corner area bends inward and shapes a longitudinal depression. As the shell moves down, the longitudinal depression deepens and widens in zones 2 to 4, and becomes stable in the subsequent cooling zones. When the shell moves through the soft reduction segments, depth and width of the longitudinal depression decrease as the marginal areas of the depressions are flattened. The model in this work is supposed to reveal an insight into the formation of consecutive longitudinal off-corner depressions at the wide face of slab during continuous casting.

https://doi.org/10.1007/s11663-021-02219-1

(C) The Minerals, Metals \& Materials Society and ASM International 2021

\section{INTRODUCTION}

HEAvY plate steel plays an irreplaceable role in the development of modern industry. They have been widely used in bridge buildings, nuclear power plants, ship buildings, offshore platforms, etc. To guarantee the performance of the final products, most heavy plates are rolled from the wide and thick continuously cast slabs, which could provide an ultrahigh reduction ratio. ${ }^{[1,2]}$ Therefore, it is of great significance to improve the quality of such slabs. During the continuous casting of a wide and thick slab, there is an intense and complex distortion of the solidifying shell, which frequently leads to consecutive longitudinal depressions within $150 \mathrm{~mm}$

ZHENYU NIU, ZHAOZHEN CAI, and MIAOYONG ZHU are with the State Key Laboratory of Rolling and Automation, Northeastern University, Shenyang 110819 and also with the School of Metallurgy, Northeastern University, Shenyang 110819, China. Contact e-mail: caizz@smm.neu.edu.cn

Manuscript submitted December 19, 2020; accepted May 4, 2021.

Article published online June 8, 2021. of the slab corners at the wide face. ${ }^{[3-5]}$ Since the wide-face longitudinal off-corner depressions are usually accompanied with other defects, such as transverse cracks in depression areas and subsurface cracks beneath depressions, the final products may be degraded or rejected if the defects are not eliminated before the rolling process. ${ }^{[6-8]}$ To avoid this scenario, most of the wide and thick slabs need to undergo time consuming and costly surface scarfing before the subsequent processing, which greatly reduces the production efficiency. As a result, frequent occurrence of the wide-face longitudinal off-corner depressions has become a general problem for wide and thick slab continuous casting.

To reveal the causes of these longitudinal depressions, many studies have been conducted via experiments and simulations. And it is well known that the steel components, properties of the mold slag, shell shrinkage, ferrostatic pressure, mold taper, etc. have certain effects on the longitudinal depression defect. ${ }^{[3,4,9-12]}$ Nevertheless, it is still unclear when, where, and how wide-face longitudinal off-corner depressions form during wide and thick slab continuous casting. In these early studies, it is believed that wide-face longitudinal 
off-corner depressions form in the mold. A large number of metallurgical examinations by Brimacombe et al.$^{[13]}$ showed that nonuniform heat transfer near the meniscus leads to thin spots on the solidifying shell, which would subsequently evolve into shell necking and longitudinal depressions under insufficient taper of the mold. Similarly, Thomas and Storkman ${ }^{[14]}$ indicated that the corners of solidifying shell would rotate in mold under an insufficient taper of the narrow face, which would separate the shell and mold walls in wide-face off-corner areas. Whereas, Mahapatra et al. ${ }^{[15]}$ proposed that the excessive taper could buckle the wide faces of solidifying shell and finally lead to the longitudinal off-corner depressions as well as the associated subsurface cracks. Recently, both of the above mechanisms were numerically studied by Zappulla et al. ${ }^{[16-18]}$ through 2D thermomechanical models. Applying tension on a solidifying shell with thickness of $3 \mathrm{~mm}$, the simulation successfully predicted a U-shaped longitudinal depression with depth of $0.58 \mathrm{~mm}$ when the tensile strain reached 7.5 pct. However, a study by Li and Thomas ${ }^{[19]}$ showed that the local plastic strain of a solidifying shell can hardly reach 0.4 pct in mold during practical continuous casting.

Since the plastic distortion of the solidifying shell in the mold is rather slight, Thomas et al. ${ }^{[20]}$ suggested that wide-face longitudinal off-corner depressions may form in multiple stages, including the mold and secondary cooling zones. To further study the formation of wide-face longitudinal off-corner depressions, they developed a 2D slice model considering shell deformation under the mold. ${ }^{[21]}$ The simulation showed that no longitudinal depression would appear on the slab as the shell grows to a uniform thickness at the mold exit. Under the condition of nonuniform shell thickness, thin spot of the shell in the wide-face off-corner area gradually evolves into a longitudinal depression as the narrow face of the shell bulges outward between the lateral strand guide rolls. Since the 2D slice model cannot completely describe the effect of support rolls on the narrow-face bulging, which is believed to be associated with wide-face longitudinal off-corner depressions, it is still unclear whether longitudinal depressions actually form between the lateral strand guide rolls. ${ }^{[5]}$

Previous works have proposed many formation mechanisms of wide-face longitudinal off-corner depressions, and the crucial influencing factors identified include the mold taper, thermal shrinkage, ferrostatic pressure, etc. However, a full description of the precondition, initialization, evolution, and final shaping of the wide-face longitudinal off-corner depressions is still not available. Therefore, a 3D transient thermomechanical model is developed in the present work to elaborate the entire formation process of the wide-face longitudinal off-corner depression. The simulation domain includes the mold region and secondary cooling zones. And the solidification and thermal shrinkage of steel, ferrostatic pressure, and contact with copper plates and rolls are all taken into consideration. The effect of soft reduction on the finial shape of wide-face longitudinal off-corner depression is also investigated. Finally, evolution of the wide-face longitudinal off-corner depression is summarized based on the multistage shell deformation. This work is supposed to provide an insight into the formation of consecutive longitudinal off-corner depressions at the wide face during thick slab continuous casting, based on which more effective prevention measures can be proposed.

\section{MODEL DESCRIPTION}

\section{A. Geometry and Mesh}

To investigate the formation of wide-face longitudinal off-corner depressions, a 3D transient thermomechanical-coupled model featuring primary cooling in the mold and secondary cooling in the roll track is developed in the present work, as shown in Figure 1. Without consideration of the bending and straightening process, it is assumed that the thermomechanical behaviors of solidifying shell are symmetrical along the width and thickness directions through the whole process of continuous casting. Therefore, the simulated domain only covers one fourth of the mold and strand. Furthermore, the copper plates are meshed as rigid bodies that only participate in the contact and thermal analysis, and the steel strand is set as a deformable body. The thicknesses of the Ni layers that protect the copper plates from wear range linearly from $0.5 \mathrm{~mm}$ at the mold top to $1.5 \mathrm{~mm}$ at the mold exit. To reduce the computational cost, the mesh in the strand core is coarsened. The detailed layout and dimensions of the water channels at both the wide and narrow faces are shown in Figure 2. The deep channel on the margin of the narrow face has an outward inclination of $15 \mathrm{deg}$, which is designed to enhance corner cooling. The other geometric parameters of the mold are listed in Table I.

In the secondary cooling zones, the rolls are set as rigid surfaces. Considering the tangential frictions between strand and rolls that are unlikely to have influences on the longitudinal off-corner depression, the surfaces of rolls are set as smooth. The diameters and positions of the rolls are set according to the practical conditions, as shown in Figure 3. The width of the roll table decreases along the casting direction, and the roll diameter increases stepwise. In the segments 1 to 6 (from $4.24 \mathrm{~m}$ to $15.86 \mathrm{~m}$ below the meniscus), the diameters of the driving rolls are higher than those of the driven ones. Meanwhile, in the straightening and horizontal segments, all of the rolls have the same diameters. At $21.16 \mathrm{~m}$ below the meniscus, the strand enters the soft reduction section, which includes segments $\# 9, \# 10$, and $\# 11$. Half of the total reduction amount reaches approximately $3 \mathrm{~mm}$ at $27.96 \mathrm{~mm}$.

\section{B. Mathematical Model}

\section{Solidification and Heat Transfer Model}

The heat transfer in the strand and mold copper plates can be described by the transient conduction equations, as shown in Eqs. [1] and [2]: 

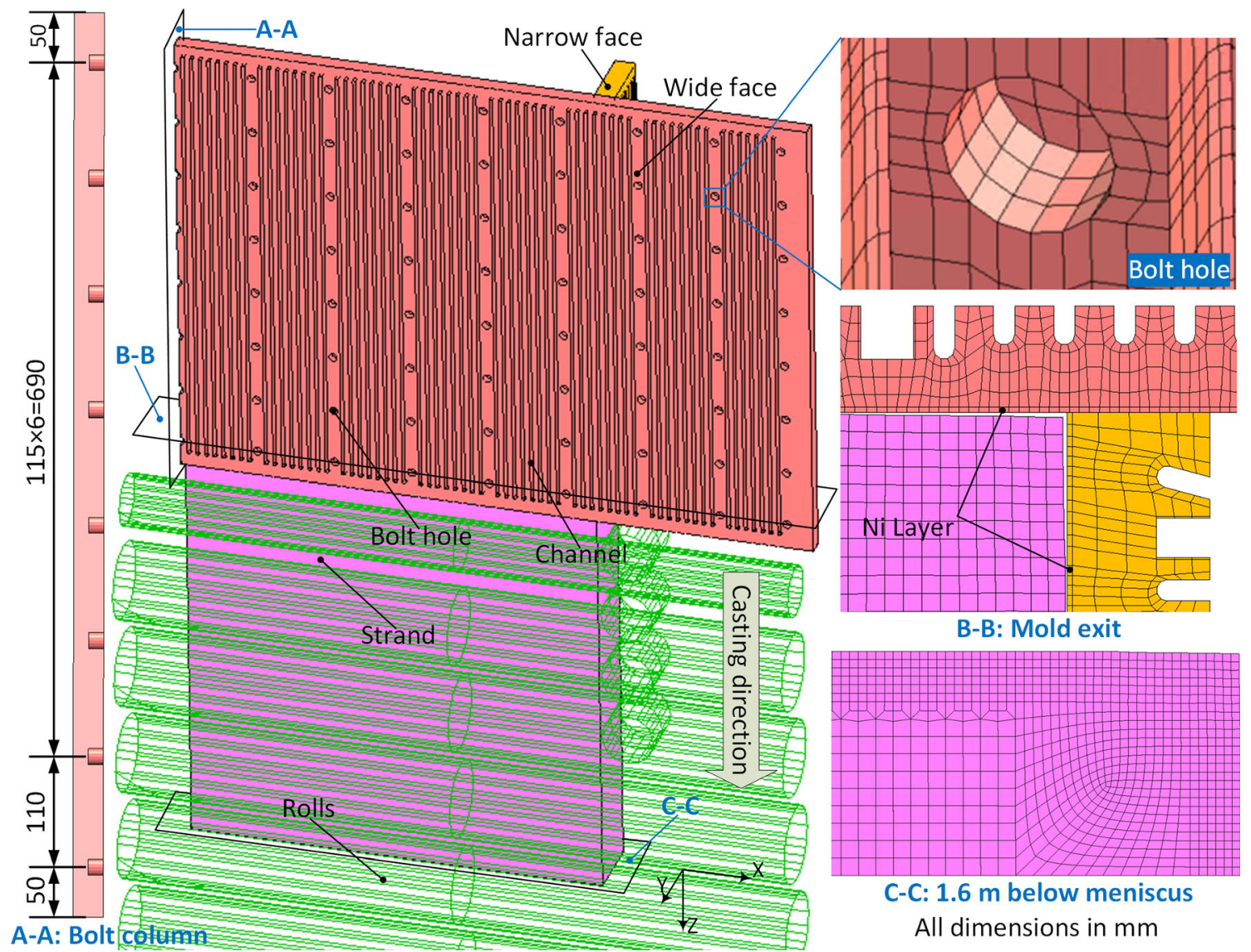

C-C: $1.6 \mathrm{~m}$ below meniscus

All dimensions in $\mathrm{mm}$

Fig. 1-Meshed assembly and geometric contact bodies.

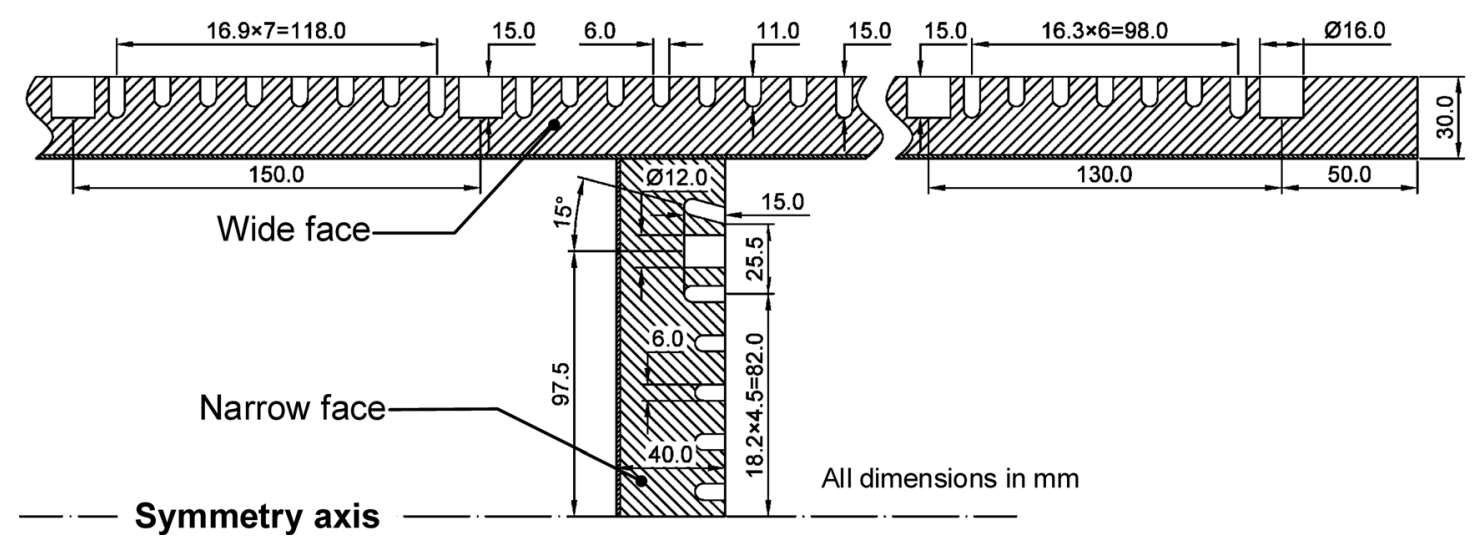

Fig. 2-Layout and dimensions of the water channels.

$$
\begin{gathered}
\rho_{s}\left(T_{s}\right) \frac{\partial H\left(T_{s}\right)}{\partial t}=\nabla \cdot\left(k_{s}\left(T_{s}\right) \nabla T_{s}\right), \\
\rho_{m} c_{m} \frac{\partial T_{m}}{\partial t}=\nabla \cdot\left(k_{m}\left(T_{m}\right) \nabla T_{m}\right) .
\end{gathered}
$$

Herein, $t$ is the current time and $T_{s}$ and $T_{m}$ are the temperatures of the steel and mold copper plates. The temperature-dependent thermal properties of the steel, including enthalpy $H\left(T_{s}\right)$, density $\rho_{s}\left(T_{s}\right)$, and conductivity $k_{s}\left(T_{s}\right)$ are obtained from the empirical formulas summarized by $\mathrm{Li}$ and Thomas. ${ }^{[19]}$ And the relevant phase fractions of liquid, $\delta$-ferrite, and $\gamma$-austenite are 
Table I. Geometry of the Mold

\begin{tabular}{ll}
\hline Item & Value \\
\hline Mold height (mm) & 900 \\
Effective mold height (mm) & 800 \\
Section dimensions of mold exit (mm) & $1600 \times 263.5$ \\
Section dimensions of mold top (mm) & $1617.6 \times 265.5$ \\
Half width of wide face (mm) & 1230 \\
Thickness of wide face $(\mathrm{mm})$ & 30 \\
Thickness of narrow face $(\mathrm{mm})$ & 40 \\
Diameter of wide-face bolt holes (mm) & 16 \\
Diameter of narrow-face bolt holes $(\mathrm{mm})$ & 12 \\
Depth of bolt holes (mm) & 15 \\
Depth of deep channels (mm) & 15 \\
Depth of shadow channels (mm) & 11 \\
Height of channels (mm) & 850 \\
Width of channels (mm) & 6 \\
\hline
\end{tabular}

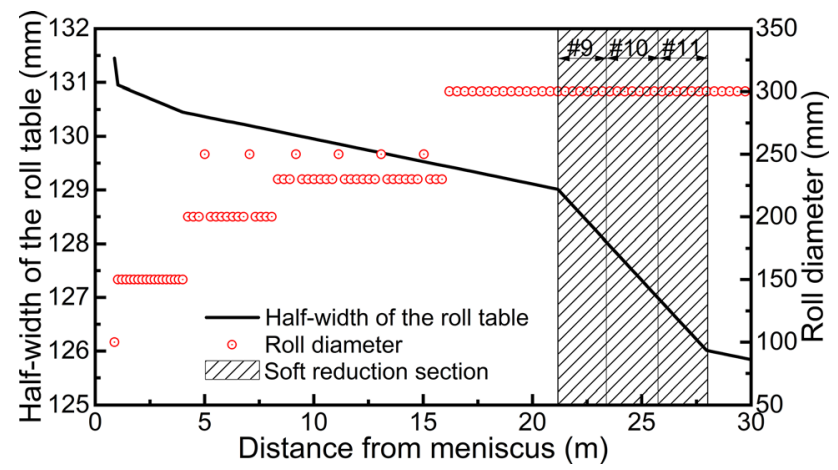

Fig. 3-Evolutions of roll space and diameter.

obtained from the microsegregation model. ${ }^{[22]}$ For the mold copper plates, $\rho_{m}$ and $c_{m}$ denote the density and specific heat, respectively, and $k_{m}\left(T_{m}\right)$ is the temperature-dependent conductivity. The thermal properties of the mold copper plates are provided in the previous work by Liu and Zhu. ${ }^{[23]}$

To accomplish the finite element simulation, the steel temperatures at the meniscus are initialized according to the temperature of molten steel in tundish. With the exception of the hot faces and channel walls, the other surfaces of mold copper plates are regard as insulated, as shown in Eq. [3] As for the steel stand, the symmetry sections and end sections of the strand are insulated, as shown in Eq. [4]:

$$
\begin{gathered}
-k_{m}\left(T_{m}\right)\left(\nabla T_{m}\right) \cdot \boldsymbol{n}=0, \\
-k_{S}\left(T_{s}\right)\left(\nabla T_{s}\right) \cdot \boldsymbol{n}=0,
\end{gathered}
$$

where $\boldsymbol{n}$ is the normal vector.

To describe the complex heat transfer between the solidifying shell and mold copper plates, an interface heat transfer model (IHTM) featuring the properties and distributions of mold slag layers, air gap expansion, and contact status is applied in the present work. ${ }^{[24]}$ In the IHTM, there are three kinds of media in the shell-mold interface gap: liquid slag, solid slag, and air. When the shell surface temperature is higher than the solidification temperature of mold slag, the interface gap is filled with liquid slag and solid slag; otherwise, it is filled with solid slag and air. Based on the conservation of energy, the interfacial heat flux and distributions of the media could be obtained by coupling with the thermomechanical model. Moreover, thermal profiles of the water channel walls are described by the fluid-structure interaction model, ${ }^{[25]}$ which takes the flow and heating of cooling water into consideration.

In the secondary cooling stage, it is assumed that the spray cooling and radiative cooling pervade all over the wide face of slab, and the transverse distribution of water flux in each cooling zone would be measured in advance. $^{[26]}$ Meanwhile, the tangent area between slab and rolls would be detected by the nodal displacements of shell surfaces and positions of geometries of rolls, and returned as a scalar, based on which the contact heat transfer with rolls is determined. ${ }^{[27]}$ Overall, the shell surface is cooled by three simultaneously applied methods, namely, spray cooling, roll contact cooling, and radiation cooling, which can be described by Eq. [5]:[26]

$$
q=h_{\text {spray }}\left(T_{s}-T_{w}\right)+h_{\text {cont }}\left(T_{s}-T_{r}\right)+\varepsilon \sigma\left(T_{s}^{4}-T_{\mathrm{amb}}^{4}\right) .
$$

Herein, $T_{w}, T_{r}$, and $T_{\mathrm{amb}}$ are the temperatures of the cooling water, rolls, and ambient air, respectively, and $h_{\text {spray }}$ is the heat transfer coefficient of the spray, which can be determined by the temperature and amount of cooling water. ${ }^{[28]} h_{\text {cont }}$ is the heat transfer coefficient of the roll contact, which is approximately $1 \mathrm{~kW} /\left(\mathrm{m}^{2} \cdot \mathrm{K}\right)$ according to the study by Xia and Schiefermuller ${ }^{[29]} \varepsilon$ and $\sigma$ are the emissivity and Stefan-Boltzmann coefficients, respectively. The values of these parameters are listed in Table II.

\section{Stress model}

Based on the finite element method, the relation between force and displacement in the stress model can be described by Eq. [6]:

$$
\boldsymbol{K} \boldsymbol{u}_{s}=\boldsymbol{F} .
$$

Herein, $\boldsymbol{K}$ denotes the stiffness matrix, $\boldsymbol{u}_{S}$ denotes the nodal displacement of the solidifying shell, and $\boldsymbol{F}$ denotes the force vector.

The strain-displacement and stress-strain relations in terms of the nodal displacement of the elements are shown in Eqs. [7] and [8]:

$$
\boldsymbol{\varepsilon}_{e l}=\beta \boldsymbol{u}_{e l},
$$

$$
\boldsymbol{\sigma}_{e l}=L \boldsymbol{\varepsilon}_{e l} .
$$

Herein, $\boldsymbol{\varepsilon}_{e l}$ and $\boldsymbol{\sigma}_{e l}$ denote the strain and stress tensors of the elements, respectively, and $\beta$ and $L$ denote the strain-displacement and stress-strain relations, respectively. $\boldsymbol{u}_{e l}$ denotes the displacement vector associated with element nodes. 
Table II. Parameters Associated With the Thermal Analysis

\begin{tabular}{ll}
\hline Parameters & \multicolumn{1}{c}{ Values } \\
\hline Temperature of cooling water $(\mathrm{K})$ & 298 \\
Roll temperature $(\mathrm{K})$ & 423 \\
Ambient temperature $(\mathrm{K})$ & 298 \\
Heat transfer coefficient of roll contact $(\mathrm{W} /$ & 1000 \\
$\left.\quad\left(\mathrm{~m}^{2} \cdot \mathrm{K}\right)\right)$ & \\
Emissivity & 0.8 \\
Stefan-Boltzmann coefficient $\left(\mathrm{W} /\left(\mathrm{m}^{2} \cdot \mathrm{K}\right)\right)$ & $5.67 \times 10^{-8}$ \\
\hline
\end{tabular}

During practical continuous casting, the creep behavior of the solidifying shell at high temperatures may have a significant influence on its deformation. Therefore, an elasto-viscoplastic constitutive model developed by Kozlowski et al. ${ }^{[30]}$ is incorporated into this stress model, as shown in Eq. [9]:

$$
\begin{aligned}
\dot{\bar{\varepsilon}} & =C \exp \left(\frac{-17160}{T_{s}}\right) \bar{\sigma}^{n} t^{m} \\
C & =0.3091+0.209 w_{c}+0.1773 w_{c}^{2} \\
n & =6.365-4.521 \times 10^{-3} T_{s}+1.439 \times 10^{-6} T_{s}^{2} \\
m & =-1.362+5.761 \times 10^{-4} T_{s}+1.982 \times 10^{-8} T_{s}^{2}
\end{aligned}
$$

Herein, $\dot{\bar{\varepsilon}}$ denotes the equivalent strain rate, $\bar{\sigma}$ denotes the equivalent stress, $t$ denotes the current time, $C$ denotes the pre-exponential factor, which depends on the carbon content in the steel $w_{c}, n . m$ denote the stress and time exponents, which depend on the steel temperature $T_{s}$.

To load ferrostatic pressure on the solidification front, all of the slab elements are checked. If the solidus of steel crosses through an element, a pressure would be loaded on the corresponding face of the element. The detailed loading method has been described by Liu et al. ${ }^{[31]}$ The ferrostatic pressures at different locations are obtained by Eq. [10]:

$$
P=\rho_{s}\left(T_{s}\right) g h .
$$

Herein, $g$ denotes the gravity acceleration, $h$ denotes the metallic bath depth, and $\rho_{s}\left(T_{s}\right)$ denotes the molten steel density at $T_{s} \mathrm{~K}$.

The nodal displacements of the mold are fixed as 0 , and those on the symmetric planes of the slab can be expressed by Eq. [11]. In addition, displacements of the nodes at the bottom of steel strand are expressed by Eq. [12]:

$$
\begin{aligned}
& \boldsymbol{u}_{s} \cdot \boldsymbol{n}=0, \\
& w=V_{c} \Delta t .
\end{aligned}
$$

Herein, $\boldsymbol{n}$ denotes the normal vector, $w$ denotes the displacement along the casting direction, and $V_{c}$ is the casting speed.
Table III. Computational Model Mesh Details

\begin{tabular}{lrr}
\hline Part & Nodes & Elements \\
\hline Wide-face copper plate & 424,664 & 334,696 \\
Narrow-face copper plate & 44,216 & 34,324 \\
Steel strand & 571,527 & 534,000 \\
\hline
\end{tabular}

Based on the experimental data by Mizukami et al. ${ }^{[32]}$ the temperature-dependent elasticity modulus of steel could be obtained by Eq. [13] which could be used in the temperatures between $1173 \mathrm{~K}$ and liquidus. ${ }^{[30]}$ At the temperature above liquidus, the elasticity modulus is $0.1 \mathrm{GPa}$. Poisson's ratio of the steel could be obtained by Eq. [14]: ${ }^{[33]}$

$$
E=968-2.33 T_{s}+1.9 \times 10^{-3} T_{s}^{2}-5.18 \times 10^{-7} T_{s}^{3},
$$

$$
v=0.278+8.23 \times 10^{-5} T_{s} .
$$

The thermal linear expansion coefficient (TLE) could be obtained from the evolution of the steel density during solidification, as shown in Eq. [15]:

$$
T L E=\sqrt[3]{\frac{\rho_{\mathrm{ref}}}{\rho_{s}\left(T_{s}\right)}}-1 .
$$

Herein, $\rho_{\text {ref }}$ is the steel density at room temperature.

\section{Numerical method}

The nonlinear finite element software MSC.Marc is applied to couple the solidification heat transfer model and stress model. The element type 7 used throughout the simulation is eight-node hexahedron, and the mesh details are provided in Table III. In the mold region, the subroutine UACTIVE is called to deactivate the slab elements above the meniscus and reactivate them once they move into the workspace below the meniscus.

The IHTM was built in a Fortran subroutine. During the strong coupling of thermal and mechanical analysis, $T_{s}, T_{m}$, and the corresponding contact distances are delivered into the subroutine UHTCON and UHTNRC, which would call the subroutine of IHTM and obtain the interfacial heat transfer coefficients. Afterwards, the heat transfer coefficients would be returned to the thermomechanical model to update $T_{s}$, $T_{m}$, and contact status.

Once the strand moves out of the mold, the thermal boundary conditions characterizing the spray cooling and radiative cooling are loaded on the shell surface. The contact between the strand and rolls is then activated and detected by the software according to the positions of nodes on strand surfaces and rigid surfaces of rolls. Based on the contact conditions, the corresponding displacement constraints would be automatically loaded on the nodes in contact with rolls. 
To improve the convergence and avoid penetration, which frequently occur when the elasticity modulus is low, the elements with temperatures higher than the liquidus temperature are deactivated in the stress analysis. The coupling flow chart is shown in Figure 4. Based on these approaches, the simulation ran on a 12-core 3.2 GHz Intel Xeon processor (Gold 6146) with $128 \mathrm{~GB}$ of RAM. Parallel computation was applied during the model solving, and the domain number is 8 . It took about 47 days to complete the simulation.

\section{RESULTS AND DISCUSSION}

\section{A. Model Validation}

At the backs of the mold copper plates, the thermocouples are embedded in the ribbed plates and align with the bolt columns to record the mold thermal state and avoid cohesive steel leakage. The insertion depths of thermocouples in both wide and narrow faces are $18 \mathrm{~mm}$. Under the steady continuous casting conditions shown in Tables IV and V, the calculated temperatures of the mold copper plates are compared with the signals recorded by the thermocouples, as shown in Figure 5. Compared with the previous work, ${ }^{[24]}$ the casting speed of the present work is much higher, which leads to a higher mold temperature. In the width direction, the high points of temperatures are aligned with the bolt holes. Along the wide-face centerline, thermocouples TC1, TC2, and TC3 record average temperatures of 395, 382, and $369 \mathrm{~K}$ in $5 \mathrm{~min}$, which coincide well with the predicted temperatures. In contrast, at the narrow face, there are more erratic fluctuations in the measured transient temperatures. However, the time-averaged temperatures of T4, T5, and T6 are very close to the calculated temperatures of the narrow-face centerline.

Since the duration of slab in the secondary cooling zones is much longer than that in the mold, the temperature evolution of slab in secondary cooling zones has significant influences on the final shape of wide-face longitudinal off-corner depression. Figure 6 shows the comparison between the predicted and measured temperatures at various positions of the slab. Due to the contact heat transfer, temperature of the

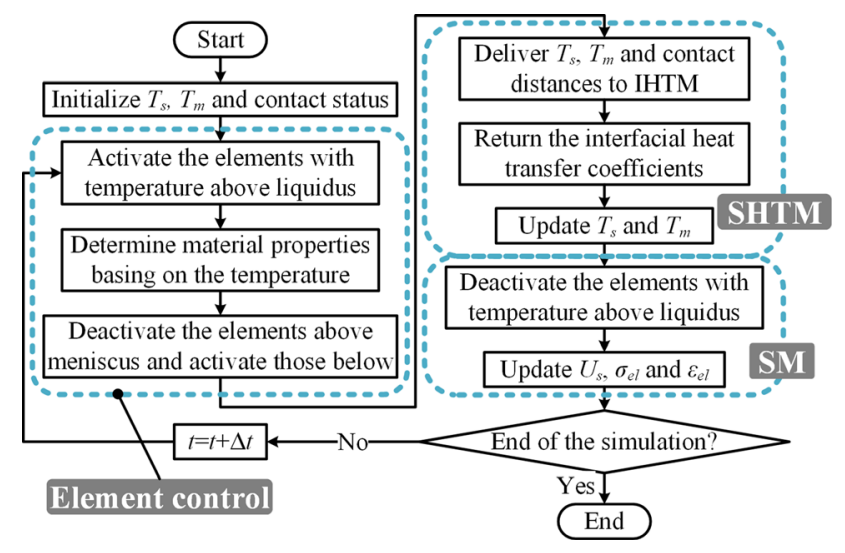

wide-face center shows a periodic fluctuation between rolls. The amplitude of the fluctuation is lower (approximately $44 \mathrm{~K}$ ) in the upper segments. With the strand moving downward, the amplitude increases to approximately $89 \mathrm{~K}$ at the lower segments. Without contact heat transfer with rolls, the wide-face area at $100 \mathrm{~mm}$ off the slab corner holds a higher temperature than the wide-face center before the soft reduction and shows no fluctuation of temperature between the adjacent rolls in zones 3 to 8 . As for the shell corner, the fluctuation of temperature occurs in zones 3 to 5 and soft reduction segments, where the corner has a substantive contact with rolls. Out of the foot roll segment, the narrow face would not be cooled by water spray, which leads to a significant temperature rise in the area. In segments 8 to 11 , the predicted temperatures of various positions are consistent with the measured, and the average relative error between the measured and predicted temperatures is 0.93 pct.

Considering that the soft reduction process may have a significant influence on the final shape of the longitudinal off-corner depression, it is necessary to accurately predict the shell deformation during the reduction process. To verify the prediction, the real-time feedback pressures recorded by the sensors on four hydraulic cylinders in each reduction segment are summed and compared with the predicted reduction pressures, as shown in Figure 7. The cylinder pressures of the three reduction segments show undifferentiated increases as the total reduction amount increases from $3 \mathrm{~mm}$ to 9 $\mathrm{mm}$. Passing through the three segments, the solid fraction and the stiffness at the slab center increase, which causes the cylinder pressure of the backward segment to be significantly higher than that of the forward segment under the same reduction amount. Figure 7(d) shows a comparison of the reduction pressures between the measured and calculated, and the maximum relative error is approximately 5.4 pct, which partly validates the simulation in the soft reduction stage.

Figure 8 shows the measured and predicted longitudinal off-corner depressions at the wide faces of slabs when the total soft reduction amount reaches $6 \mathrm{~mm}$. Since the deformation of steel slab is slight after the soft reduction, the profile of cross section of slab in the subsequent segments is very close to the final shape. Based on this, the simulation is terminated by the end of segment 12, where the predicted longitudinal off-corner depression is compared with the micrograph of a cold slab under the deformation magnification factor of $1: 1$. The measured and predicted longitudinal depressions have similar asymmetrical profiles, which shows a higher curvature at the corner side and lower curvature at the mid-face side. The width and depth of the predicted longitudinal depression are 83.71 and $1.77 \mathrm{~mm}$, respectively, and those of the measured are approximately 72.37 and $1.73 \mathrm{~mm}$, respectively. Moreover, both the measured and predicted profiles of the narrow faces of the slabs are s-shaped, which also verifies the validity of the model.

Fig. 4-Flow chart of the simulation. 
Table IV. Operating Conditions of the Slab Mold

\begin{tabular}{ll}
\hline Item & \multicolumn{1}{c}{ Value } \\
\hline Initial temperature $(\mathrm{K})$ & 1814 \\
Narrow-face taper $(\mathrm{pct})$ & 1.1 \\
Casting speed (m/min) & 1.05 \\
Wide-face water flow (L/min) & 4760 \\
Narrow-face water flow (L/min) & 530 \\
Import water temperature (K) & 305 \\
Main composition of steel (wt pct) & $0.08 \mathrm{C}-0.3 \mathrm{Si}-1.5 \mathrm{Mn}-0.013-$ \\
& P-0.003S \\
Properties of mold slag and air & Niu et al. ${ }^{[24]}$ \\
$\quad$ gap & \\
\hline
\end{tabular}

Table V. Operating Conditions of the Secondary Cooling Zones

\begin{tabular}{llcc}
\hline $\begin{array}{l}\text { Cooling } \\
\text { zone }\end{array}$ & Segments & $\begin{array}{c}\text { Length } \\
\text { (m) }\end{array}$ & $\begin{array}{c}\text { Water Amount (L/ } \\
\text { min) }\end{array}$ \\
\hline Zone 1 L/R & foot roll & 0.59 & 110 \\
Zone 1 I/O & foot roll & 0.24 & 330 \\
Zone 2 I/O & bending & 0.56 & 420 \\
Zone 3 I/O & bending & 1.11 & 405 \\
Zone 4 I/O & bending & 1.53 & 340 \\
Zone 5 I/O & 1 & 2.05 & 290 \\
Zone 6 I & 2 to 3 & 4.01 & 115 \\
Zone 7 I & 4 to 5 & 3.9 & 55 \\
Zone 8 I & 6 to 8 & 6.76 & 45 \\
Zone 9 I & 9 to 11 & 7.36 & 25 \\
Zone 10I & 12 to 14 & 7.14 & 0 \\
\hline
\end{tabular}

\section{B. Thermal and Deformation Behaviors of the Solidifying Shell in the Mold}

In the primary cooling stage, whether the longitudinal depression forms at the wide-face off-corner depends on the interaction among the shell deformation, lubricant distributions, interfacial heat transfer, and shell growth. Figure 9 shows the shell deformation, temperature distribution, and shell growth at different heights of the mold. To highlight the deformation of the solidifying shell, the shell-mold interfacial gap is magnified up to 3 times. As shown in Figure 9(a), the shell thicknesses at the wide and narrow face centers reach approximately $2.51 \mathrm{~mm}$ at $100 \mathrm{~mm}$ below the meniscus. Cooling on the shell causes drastic thermal shrinkage along the width and thickness directions, which detaches the shell corner from the mold hot faces and ultimately creates an obvious interfacial gap in the corner. With the shell moving downward to $300 \mathrm{~mm}$ below the meniscus, the shell thickness of the wide-face center increases to $8.44 \mathrm{~mm}$. Meanwhile, width of the corner gap expands to $79 \mathrm{~mm}$ at the wide-face side and $52 \mathrm{~mm}$ at the narrow-face side. Affected by the expanding corner gap, there exhibits a nonuniform distribution of shell thickness at $500 \mathrm{~mm}$ below the meniscus. The shell thicknesses at the wide- and narrow-face centers reach $12.19 \mathrm{~mm}$, while, spot at the wide face $40 \mathrm{~mm}$ off the corner reaches only $8.53 \mathrm{~mm}$. Moving close to the mold exit, shell shrinkage along the width and thickness directions are moderated. The interfacial gap at the narrow-face side begins to close under the accommodation of mold taper. Meanwhile, the corner gap at the wide-face side continues to expand. At the mold exit, difference of shell thickness between the mid-face and $40 \mathrm{~mm}$ off the corner at the wide face reaches $4.16 \mathrm{~mm}$, which has a certain effect on the surface and subsurface cracks. ${ }^{[34]}$

Although the solidifying shell has nonuniform growth in the mold region and a thin spot appears in the off-corner area, the appropriate mold taper could generally accommodate shell shrinkage along the width directions and efficiently constrain the deformation of shell corner. Therefore, formation of the wide-face longitudinal off-corner depression in the mold is greatly impeded. To further inspect the shell distortion, the normal displacements of the wide and narrow faces are shown in Figure 10. In the wide and narrow mid-faces, the shell closely contacts with the mold copper plates, and the normal displacements of shell surfaces are in line with the mold taper accommodations. Along the circumferential direction, the corner and off-corner areas undergo larger displacements than the mid-face areas. Since the nonuniform distribution of the shell temperature results in a difference in the stiffnesses between the corner and mid-faces, the variation in the normal displacements from the mid-faces to the corner is nonlinear, which may have a potential effect on the formation of wide-face longitudinal off-corner depression.

Displacements of shell corner and off-corner areas show no formation of longitudinal depression in the mold region. However, the expansion of interfacial gap between shell corner and mold copper plates leads to a hot spot at the wide-face off-corner, where the shell is about $4.16 \mathrm{~mm}$ thinner than that of the mid-face at the mold exit. Assuming the narrow faces of shell could not be sufficiently supported by the rolls in secondary cooling zones, significant deformation would occur at the thin (hot) spots of solidifying shell, which may lead to longitudinal depressions. Figure 11 shows the circumferential temperature distribution of the shell surface at different heights. The temperature distribution becomes nonuniform by $100 \mathrm{~mm}$ below the meniscus. With the solidifying shell moving downward, the nonuniformity in the distribution increases. At the mold exit, the maximum temperature of wide-face off-corner is about $128.7 \mathrm{~K}$ higher than that of wide-face center, and the hot spot distributes within $90 \mathrm{~mm}$ of the corner. As for the narrow face, the temperature difference and width of the hot spot are relatively small. The hot spot at wide-face side could lead to large austenite grains and increase the cracking susceptibility of steel, which may be the main cause of surface cracks in longitudinal depression area. ${ }^{[35]}$

\section{Thermal and Deformation Behaviors of the Solidifying Shell Below the Mold}

After primary cooling in the mold, the solidifying shell moves into the secondary cooling zones, where both contact cooling by rolls and spray cooling have a significant influence on the slab temperature. 


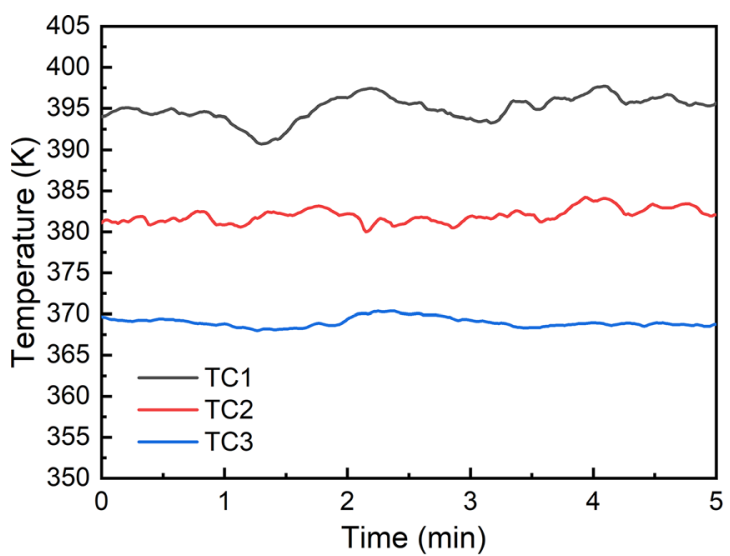

(a)

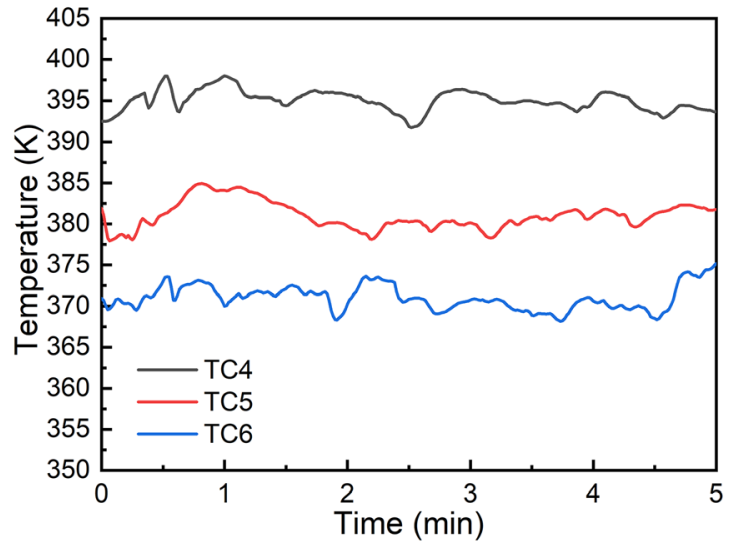

(c)

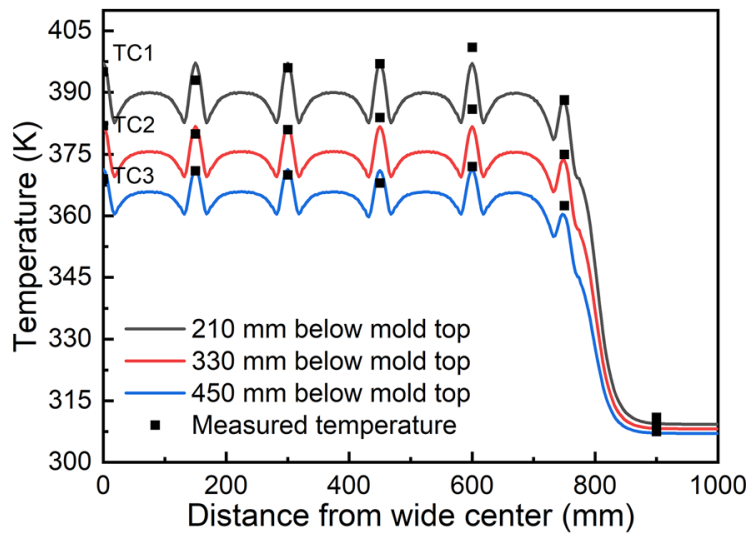

(b)

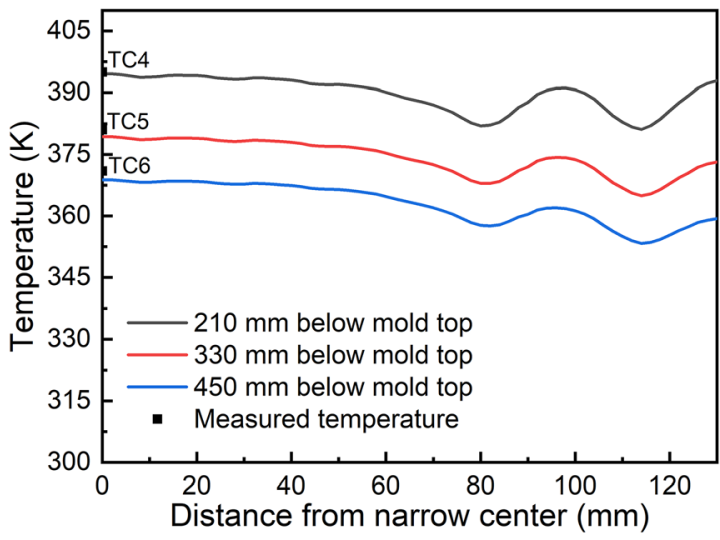

(d)

Fig. 5-Comparison between the measured and calculated mold temperatures: $(a)$ wide-face signals, $(b)$ wide-face comparison, $(c)$ narrow-face signals, and $(d)$ narrow-face comparison.

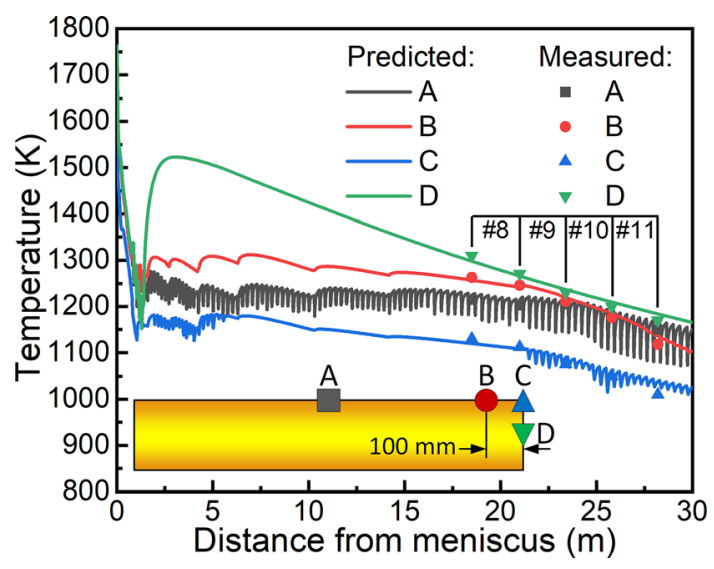

Fig. 6-Verification of the predicted temperatures at the center of the wide face of the slab.

Meanwhile, the temperature of steel strand has a certain effect on the deformation of solidifying shell. Figure 12 shows the contact state, temperature distribution, width, and thickness direction displacements of the slab just below the mold, and $Z$-axis indicates the distance from meniscus. In the central area of the wide face, the ferrostatic pressure pushes the solidifying shell outward, which maintains close contact between the slab and support rolls. Meanwhile, the distortion of the shell corner caused by thermal shrinkage creates a gap between the corner and off-corner areas and the rolls. Due to the intensive contact cooling, the temperature of wide-face center sharply decreases in the contact area. However, the off-corner hot spot inherited from the mold heat transfer persists in the secondary cooling zones because of the absence of roll contact. Figures 12(c) and (d) shows that the narrow face is pressed toward the slab center by the support rolls below the mold. Meanwhile, no significant longitudinal depression forms in the wide-face off-corner area. Moving out of the foot roll segment, the narrow face gradually bulges outward, and the longitudinal depression begins to form within $100 \mathrm{~mm}$ of the corner.

Figure 13 shows the temperature distributions of the wide face of slab at the ends of different cooling zones as well as the evolution of the off-corner temperature inhomogeneity. The maximum temperature difference between the off-corner area and wide-face center reaches $123 \mathrm{~K}$ at the mold exit and then sharply decreases to $54 \mathrm{~K}$ at the end of zone $1(\mathrm{I} / \mathrm{O})$. Although the maximum temperature difference decreases in magnitude, the qualitative tend is maintained throughout the process of secondary cooling. The average temperature 


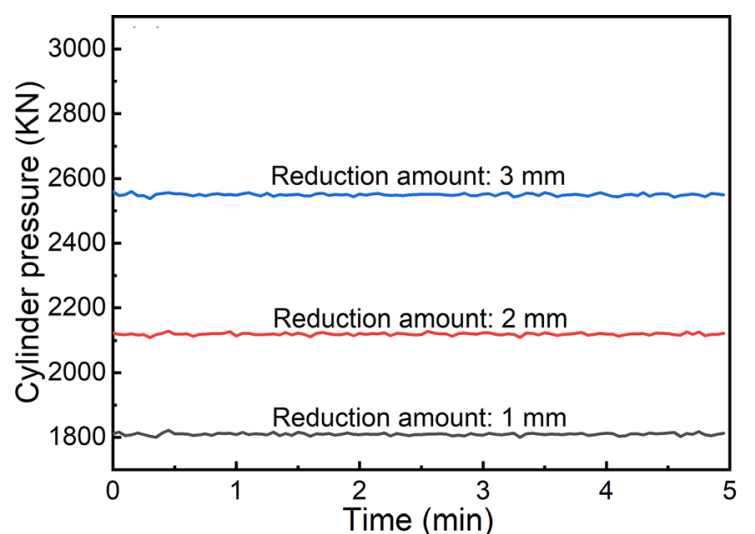

(a)

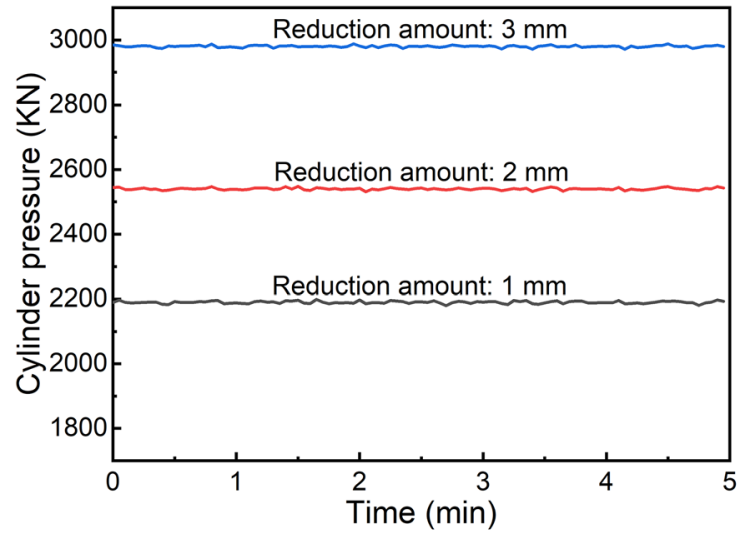

(c)

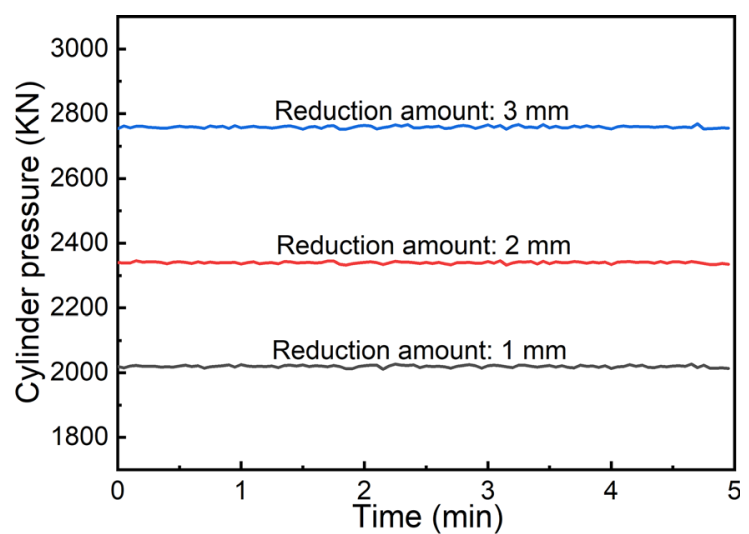

(b)

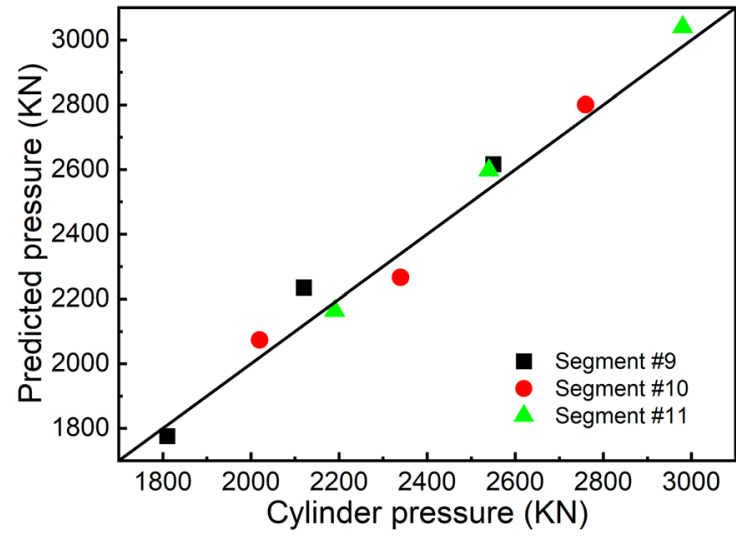

(d)

Fig. 7-Measured reactive forces at (a) segment \#9, (b) segment \#10, (c) segment \#11, and (d) their comparison with the calculated forces.

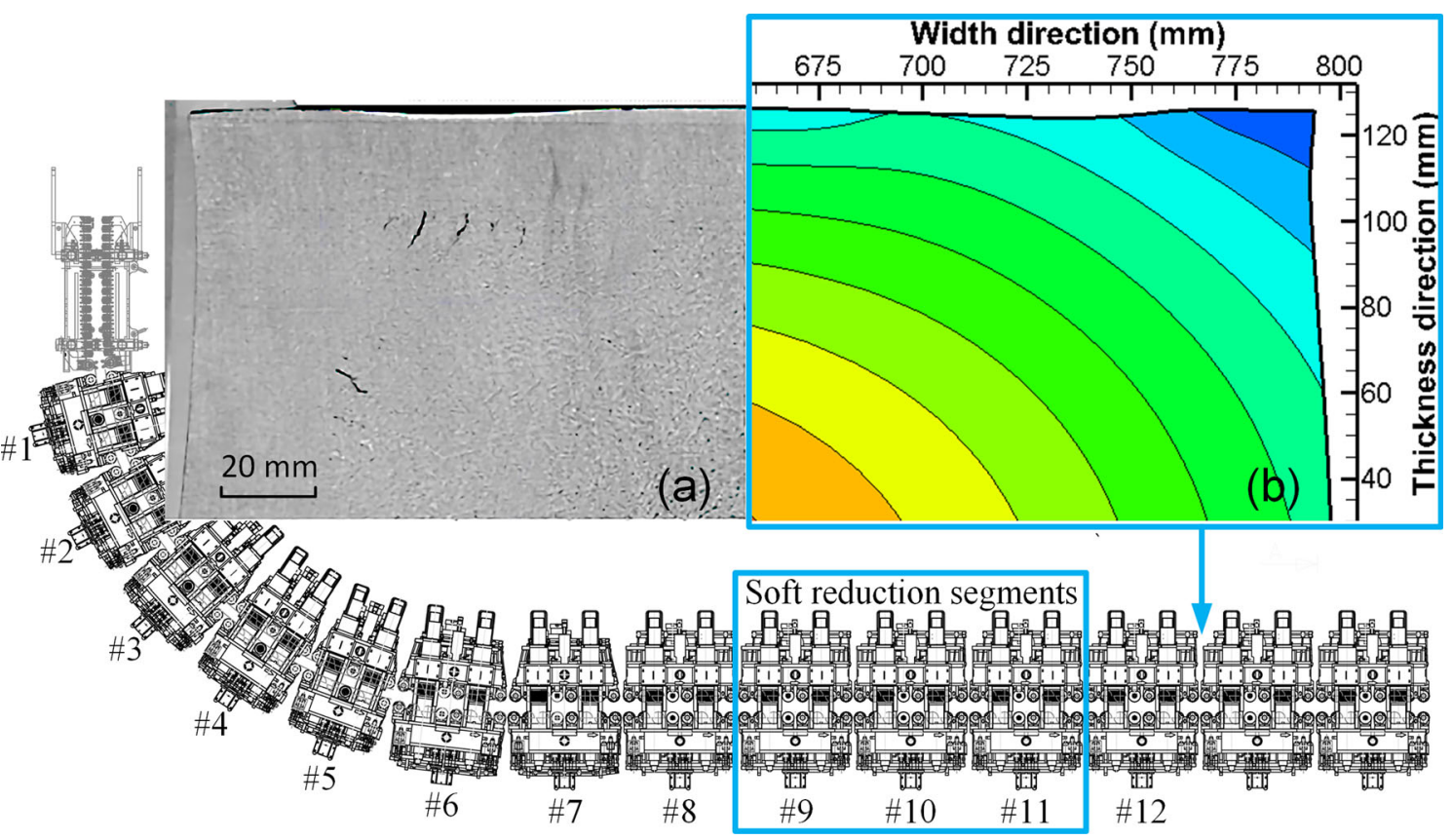

Fig. 8 - Comparison of $(a)$ measured and $(b)$ predicted longitudinal depressions. 


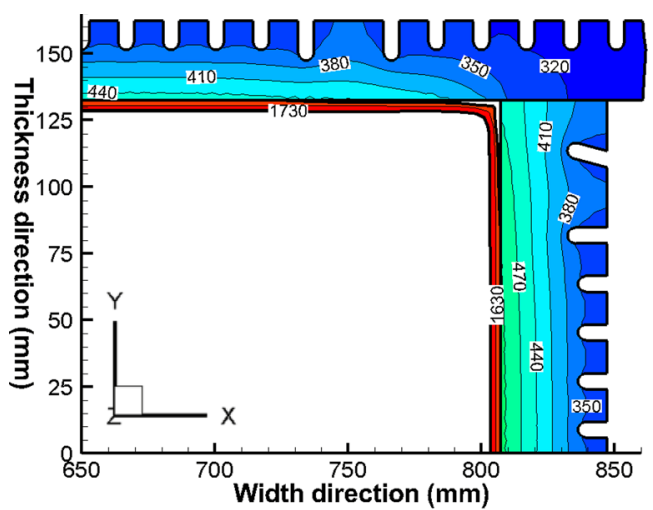

(a)

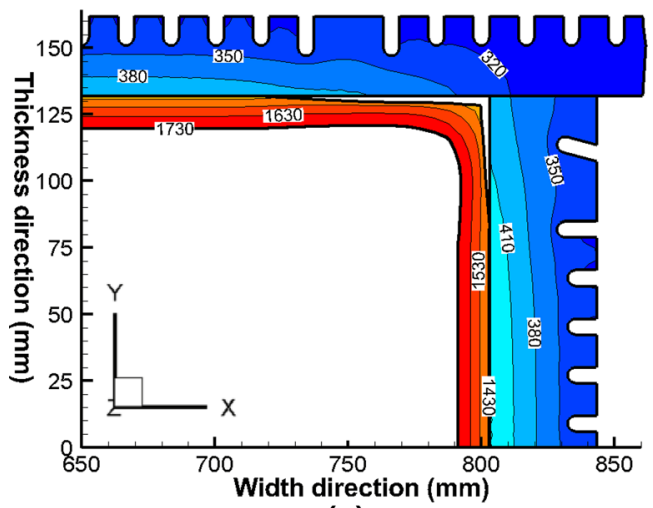

(c)

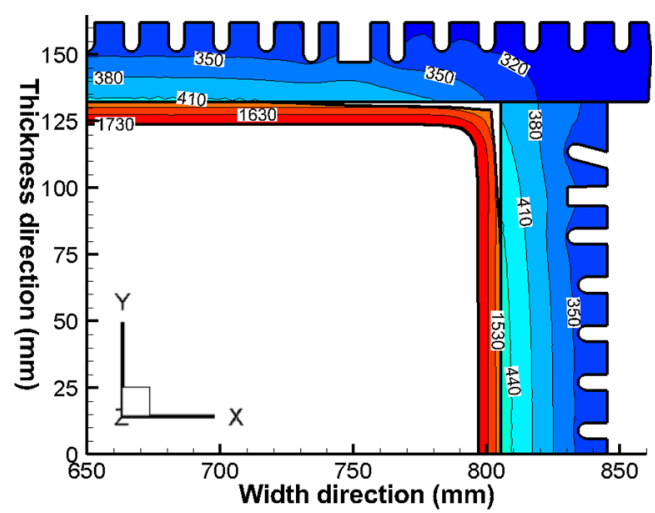

(b)

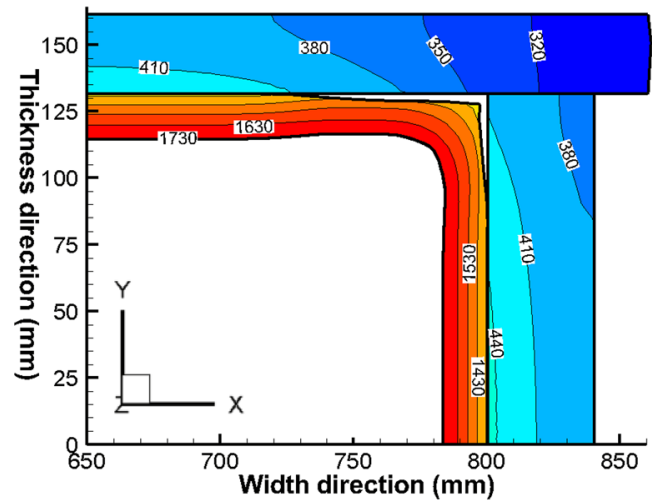

(d)

Fig. 9-Contact status between the mold and solidifying shell at (a) $100 \mathrm{~mm},(b) 300 \mathrm{~mm},(c) 500 \mathrm{~mm}$ below the meniscus, and (d) the mold exit.

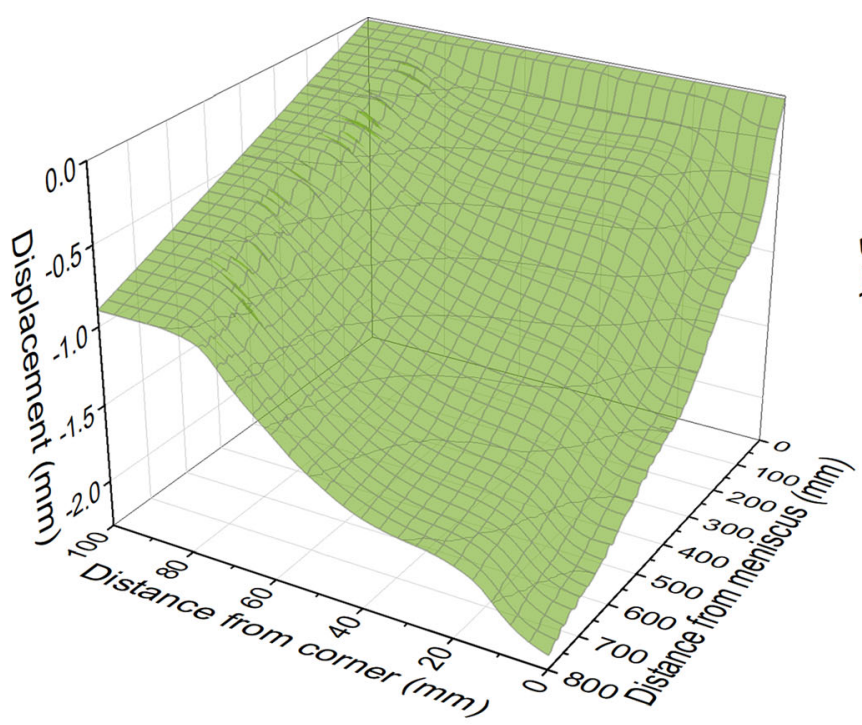

(a)

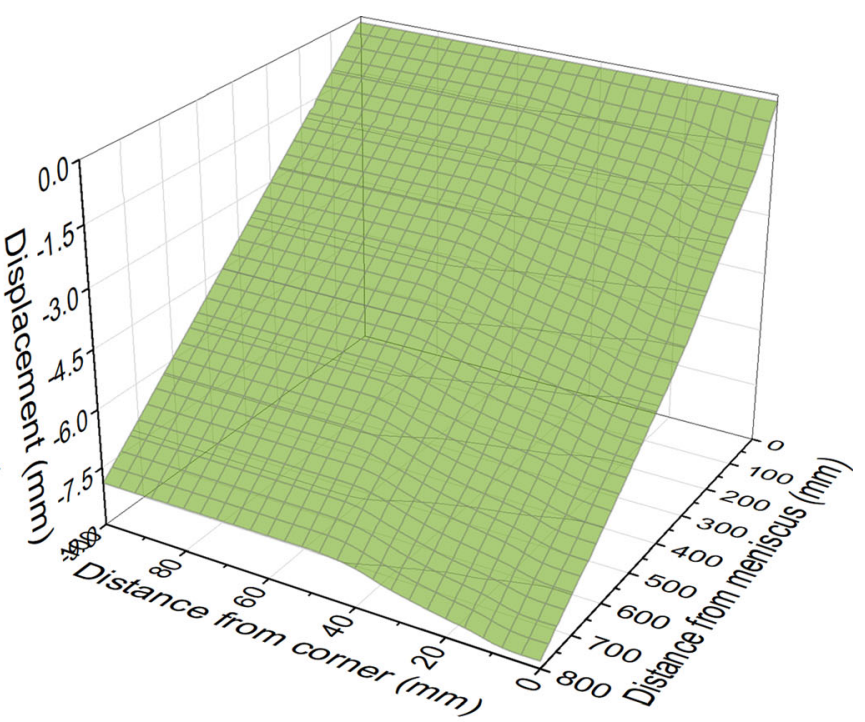

(b)

Fig. 10-Normal displacements of the corner and off-corner at the $(a)$ wide face and $(b)$ narrow face.

difference in the secondary cooling zones is approximately $75 \mathrm{~K}$. Moreover, affected by shell deformation and spray cooling, the width of the hot spot significantly increases from 93 to $189 \mathrm{~mm}$ in zones 2 to 4 . Out of zone 4 , width of the hot spot gradually stabilizes at approximately $200 \mathrm{~mm}$.
Figure 14 shows the profile of the slab margin at the ends of different cooling zones. To distinguish the evolution of shell surface, offsets of $2 \mathrm{~mm}$ in width and thickness directions are added between the outlines of adjacent zones. In zone 1, intense thermal shrinkage occurs at the shell corner. However, the support rolls at 


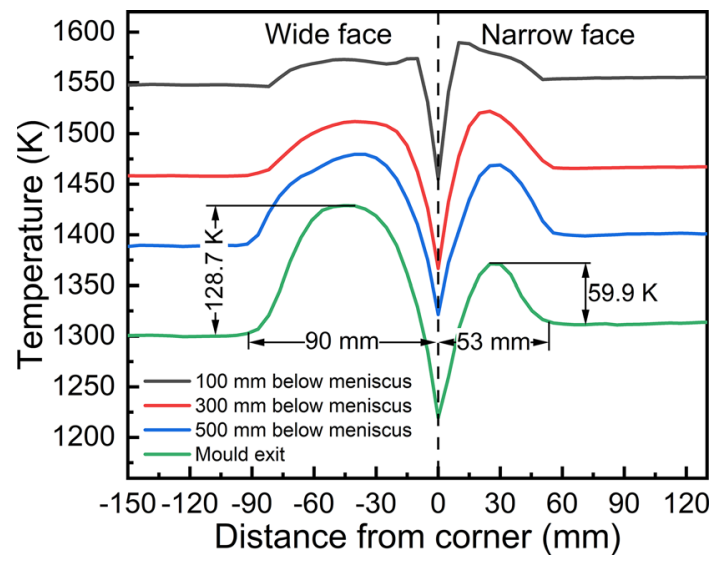

Fig. 11-Circumferential temperature distribution of the shell corner.

the narrow face accommodate this shrinkage and prevent the solidifying shell from bulging. Correspondingly, no significant longitudinal depression appears at the wide-face off-corner area. As the slab moves into zone 2, the shell at the wide face continues to shrink along the width direction. Meanwhile, the ferrostatic pressure loading on the narrow face begins to push the shell outward due to the absence of support roll there. Effected by the shell shrinkage and ferrostatic pressure, a bulge gradually forms at the narrow face, which simultaneously rotates the shell corner. Since the wideface hot spot at approximately $55 \mathrm{~mm}$ off the corner persists in the secondary cooling zones, the rotation of the shell corner causes the hot area to bend inward, and then a longitudinal depression forms in the wide-face off-corner area. The longitudinal depression considerably deepens in zones 3 to 4 . Afterward, the distortion of the shell corner is moderated.

Based on the evolution of the slab corner shape, there is a certain relation between the narrow-face bulge and wide-face longitudinal off-corner depression. Figure 15 shows the variations in the bulge amount and depression depth in the secondary cooling zones. The formation of the bulge at the narrow face and formation of the longitudinal off-corner depression at the wide face occur synchronously, which could also be observed by the displacements of shell shown in Figure 12. In zone 1, the bulge amount decreases under the pressure of the narrow-face support rolls. Meanwhile, no longitudinal off-corner depression forms at the wide face. In zones 2 to 3 , where the narrow face is not supported by roll, both the bulge amount and depression depth increase significantly. In zones 4 to 5 , the increases in bulge amount are moderated because the solidifying shell grows thick enough to resist the deformation caused by the ferrostatic pressure. Correspondingly, the deepening of the longitudinal depression slows. By the end of zone 6 , the bulge amount and depression depth reach approximately 7.24 and $3.63 \mathrm{~mm}$, respectively.

Since subsurface cracks frequently occur beneath wide-face longitudinal off-corner depressions, the normal plastic strain in the width direction is studied, as shown in Figure 16. Under the complex deformation of solidifying shell, tensile strain begins to form in the area beneath the wide-face off-corner by the end of zone 1 . Moving into zone 2, the slab corner begins to rotate, and the longitudinal depression forms at the wide-face off-corner area, which leads to the increases of tensile plastic strain at the solidification front and compressive strain in the depression area. The tensile and compressive strains reach their extrema of approximately 0.048 and -0.037 , respectively, by the end of zone 4 . Afterward, the plastic strain distributions exhibit no significant changes. Based on the evolution of the tensile plastic strain, subsurface cracks may form in zones 2 to 3 , where the rate of strain reaches the maximum.

\section{Evolution of Longitudinal Depression During Soft Reduction}

Considering that soft reduction may have a certain effect on the final shape of the longitudinal depression, the deformation of the slab in the soft reduction segments is studied, as shown in Figure. 17. Offsets between the adjacent outlines are $2 \mathrm{~mm}$ in width and thickness directions. Before the soft reduction, the longitudinal depression caused by the rotation of shell corner extends to the corner point. During the soft reduction of the slab, the longitudinal depression is partly flattened by the reduction rolls at the margins. Meanwhile, both the width and depth of the longitudinal depression decrease. It should be noted that no longitudinal depression forms at the narrow-face offcorner area at the beginning of soft reduction. However, the reduction rolls extend the wide face of slab in the width direction and finally buckle the narrow face into an s-shape. As a result, a shallow longitudinal depression appears at the narrow-face side within $20 \mathrm{~mm}$ of the corner by the end of soft reduction.

The evolutions of width and depth of the wide-face longitudinal off-corner depression during soft reduction are shown in Figure 18. Before the soft reduction, the width and depth slowly increase to 164.13 and $3.86 \mathrm{~mm}$. During soft reduction, the longitudinal depression becomes shallow and narrow. The rates of decreases in the width and depth are lower in segment 9, gradually increase to their maximums in segment 11, and significantly decrease in segment 12. By the end of soft reduction, the width and depth of the longitudinal depression decrease to 83.81 and $1.77 \mathrm{~mm}$, respectively. In the subsequent segment 12, shape of the longitudinal depression would not change significantly.

\section{E. Formation Mechanism of Wide-Face Longitudinal Off-Corner Depression}

Based on the thermomechanical behaviors of the slab throughout the continuous casting process, the formation mechanism of consecutive longitudinal depression in the wide-face off-corner area of thick slab is summarized, as shown in Figure 19. In the mold region, the shell corner detaches from the mold walls under the effect of thermal shrinkage and leaves a large shell-mold interfacial gap around the corner. The large interface gap impedes the heat transfer there, which ultimately 

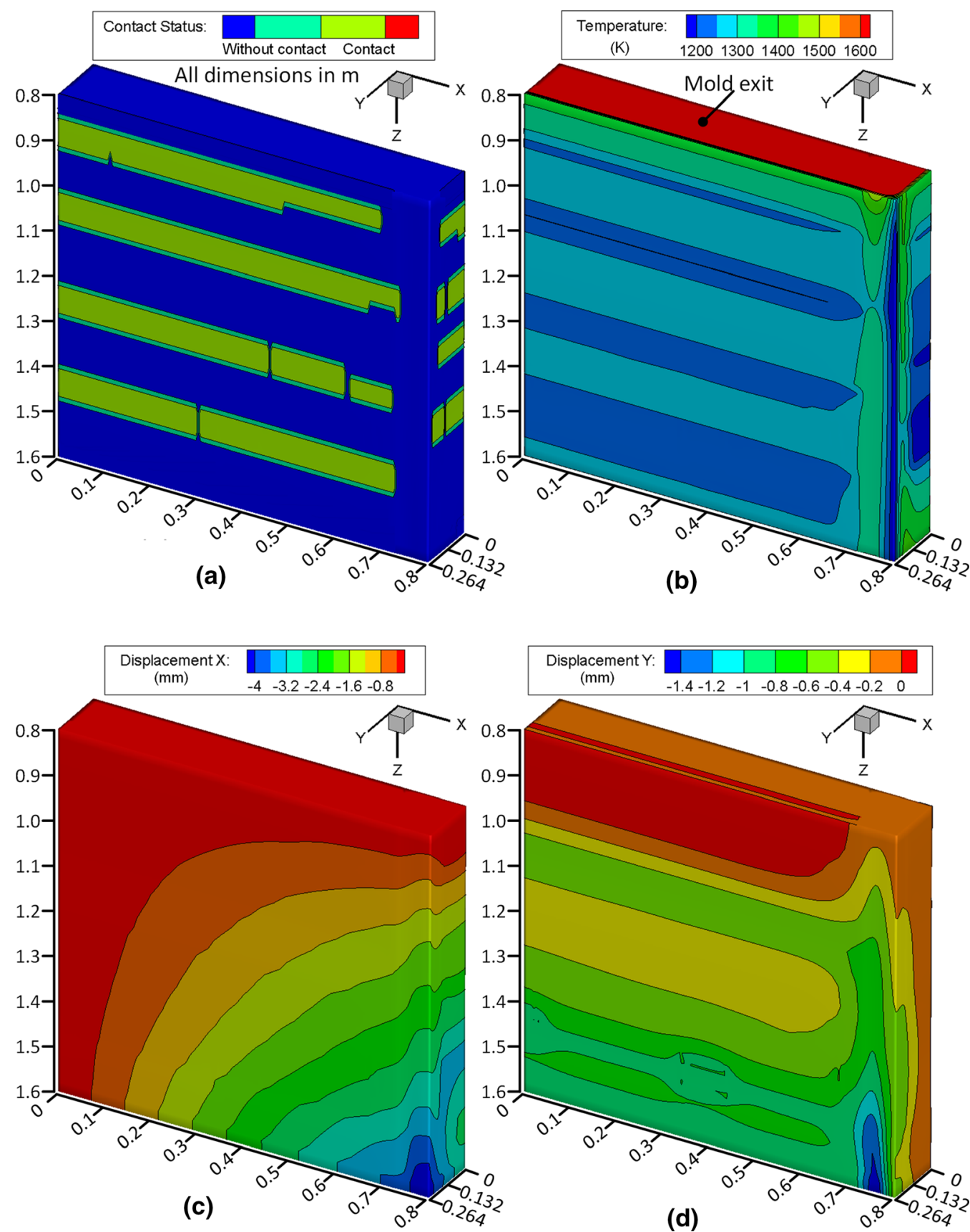

Fig. 12-Thermomechanical behaviors of the slab below the mold: $(a)$ contact state, $(b)$ temperature, and displacements in the $(c)$ width and $(d)$ thickness directions.

leads to the formation of a thin spot in the wide-face off-corner area, as shown in Figure 19(a). Moving out of the mold, the solidifying shell passes through the foot roll segment. Support rolls at the narrow face counteract the effect of the ferrostatic pressure, and no longitudinal depression forms at the wide-face off-corner area. In the subsequent segment, the narrow face begins to bulge, and the shell corner rotates under the combined effect of thermal shrinkage and ferrostatic pressure. Meanwhile, longitudinal depression initially forms at the thin spot, which is inherited from shell growth in the mold region. As the shell thickens, the increases in depression depth and width are moderated in zones 5 to 8 . In the soft reduction segments, rolls compact the slab thickness and extend the slab in width direction. Under the reduction rolls, the narrow face bends into an s-shape, while the wide-face longitudinal off-corner depression becomes increasingly shallower. 


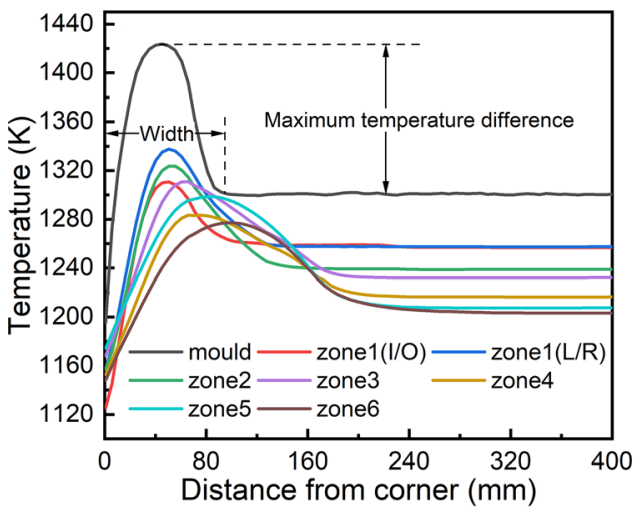

(a)

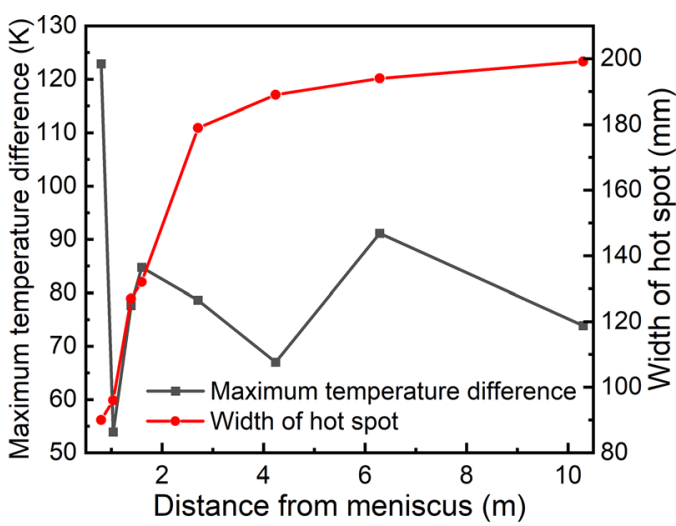

(b)

Fig. 13-Temperature evolution of the slab surface: $(a)$ transverse distributions at the ends of cooling zones, $(b)$ temperature difference and width of the hot spot.

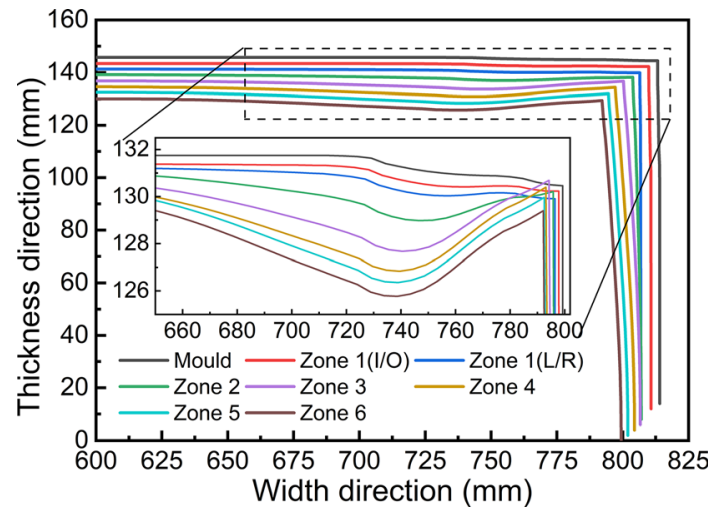

Fig. 14-Profile of the slab corner and off-corner areas.

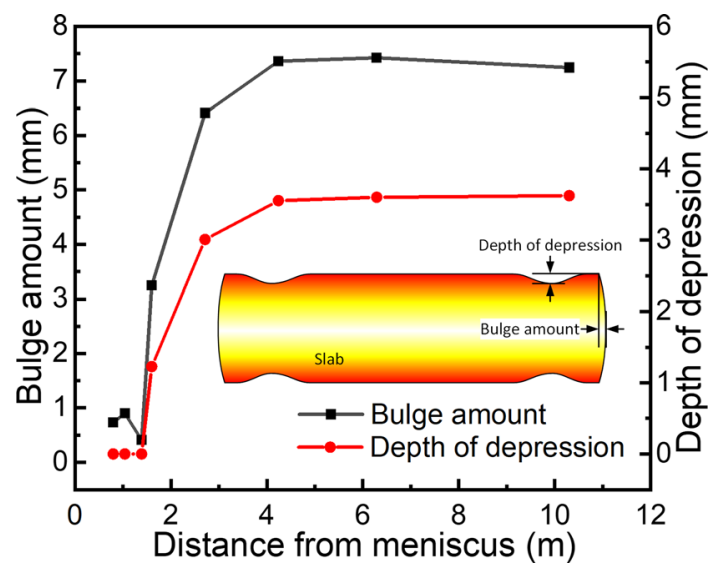

Fig. 15-Evolution of bulge amount and depth of longitudinal depression.

The mechanism proposed in the present work partly coincides with the 2-stage mechanism by Thomas et al. ${ }^{[21]}$ especially in terms of precondition and initialization of the longitudinal off-corner depression. However, there is a significant difference between the two mechanisms about where exactly the longitudinal depression initially forms. The previous work emphasizes that the longitudinal off-corner depressions initially form in the foot roll segment, while the present work supposes that the longitudinal depressions initially form below the lateral strand guiding rolls. Furthermore, the present work elucidates not only the initialization but also evolution and finally shaping of the longitudinal depression, which have been seldom described in the previous works. The mechanisms in other previous works ${ }^{[8,13,15-18]}$ give insights into the longitudinal depressions on billet/slab which frequently occur in inappropriate operation conditions like excessive and insufficient mold tapers, nonuniform heat transfer, etc, while the practical production shows that the consecutive longitudinal depressions may occur in the wide-face off-corner of thick slab under appropriate casting conditions. The present work may provide an insight into this type of longitudinal depression.

According to the present mechanism, extending the length of foot roll segment to the end of zone 3 could avoid the defect of the longitudinal depression. Reducing the casting speed and increasing the cooling on narrow-face and wide-face off-corner may also be helpful, while the practical effect needs further demonstration.

\section{CONCLUSIONS}

A numerical model is developed to study the formation mechanism of longitudinal depressions in wide-face off-corner areas during thick slab continuous casting. Considering that the longitudinal depression may not form in a single stage, the simulation covers the entire process, including primary cooling in the mold, secondary cooling in the roll bed and final transformation in the reduction segments. Based on the simulation, the main conclusions are summarized as follows:

1. In the general case where the mold copper plates could constrain the plastic deformation of solidifying shell under an appropriate taper, the deviation between shell shrinkage and taper accommodation can only lead to a large interfacial gap rather than a 


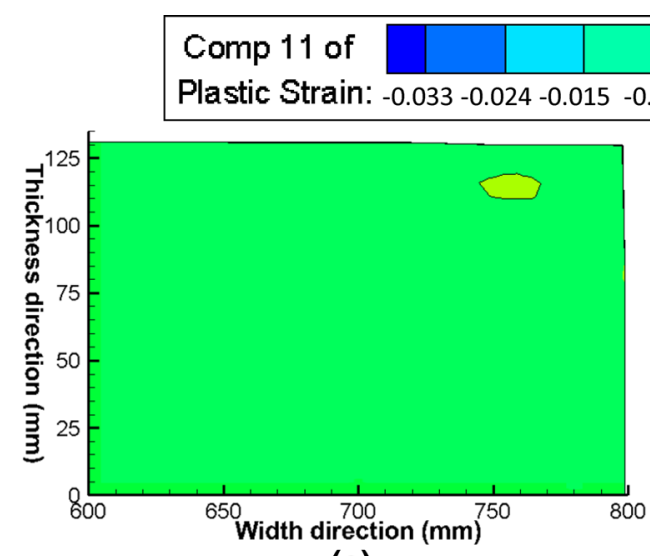

(a)

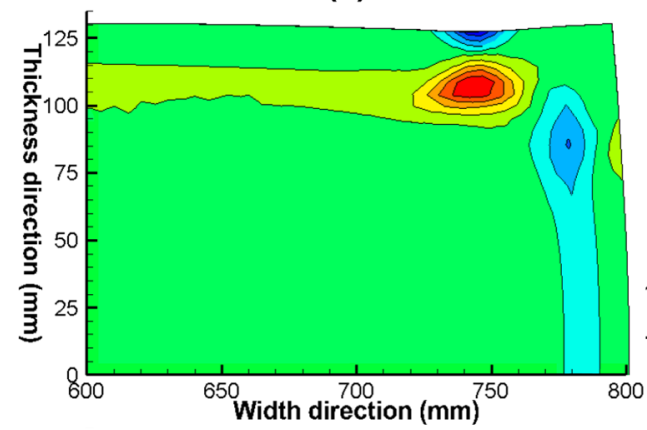

(c)

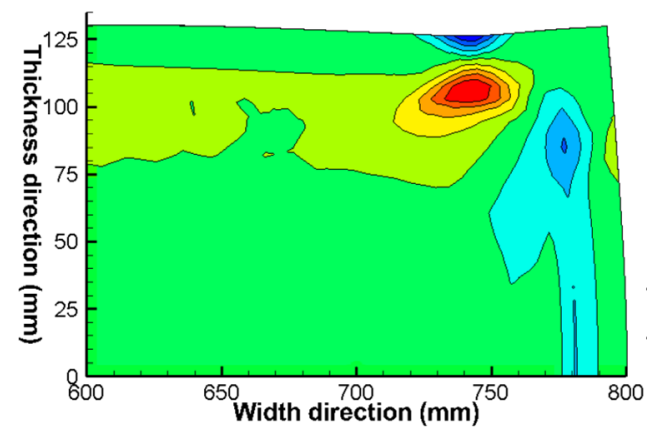

(e)

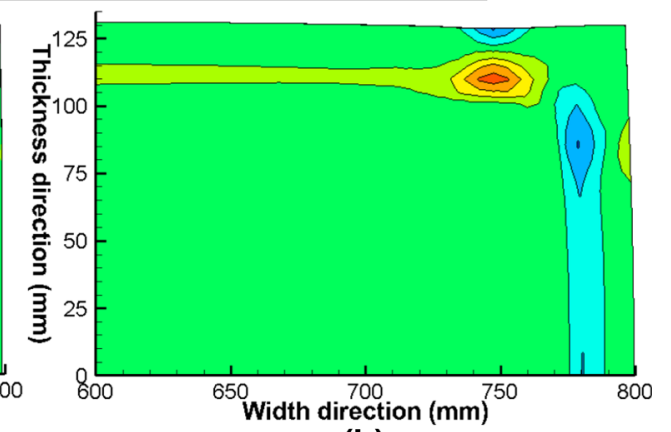

(b)

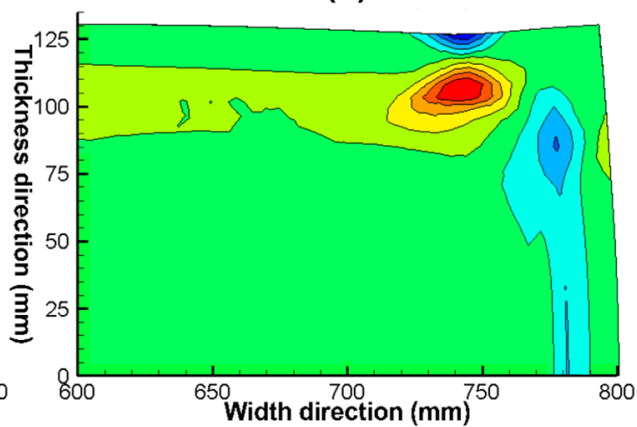

(d)

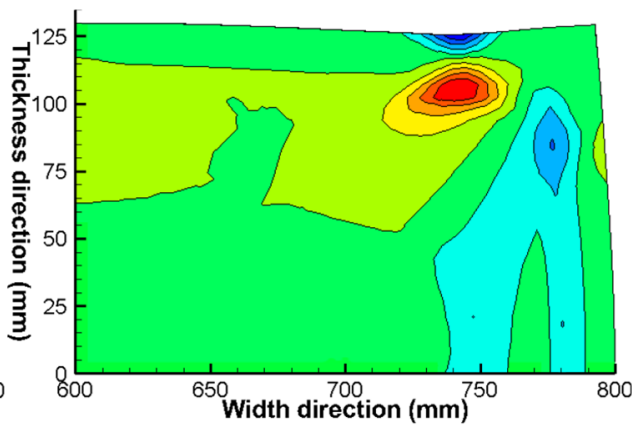

(f)

Fig. 16 - Component 11 of plastic strain in the width direction at the end of $(a)$ zone $1,(b)$ zone 2, $(c)$ zone 3 , (d) zone 4, (e) zone 5, and $(f)$ zone 6.

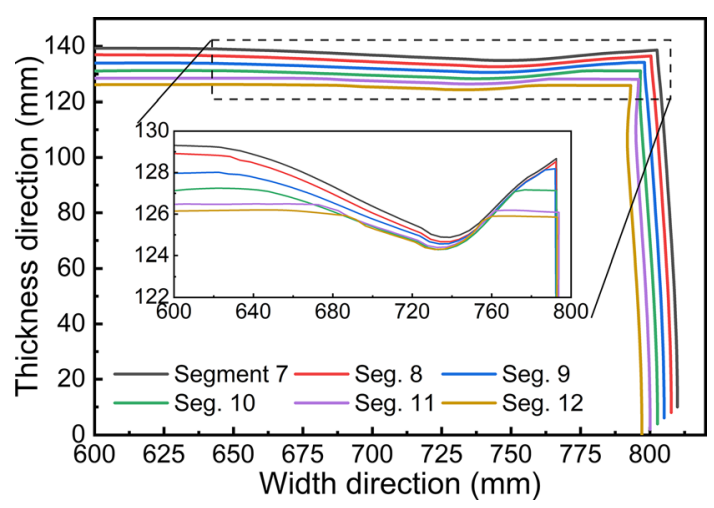

Fig. 17-Profile of wide-face longitudinal off-corner depression during soft reduction.

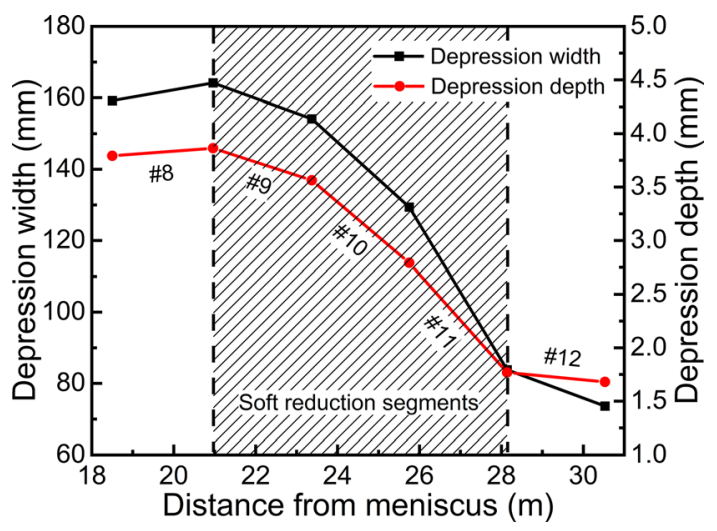

Fig. 18-Evolution of width and depth of longitudinal depression during soft reduction. 


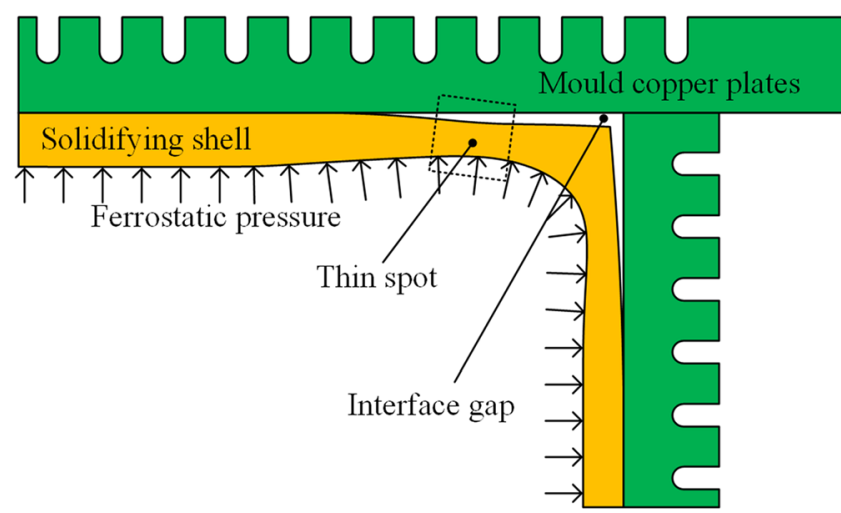

(a)

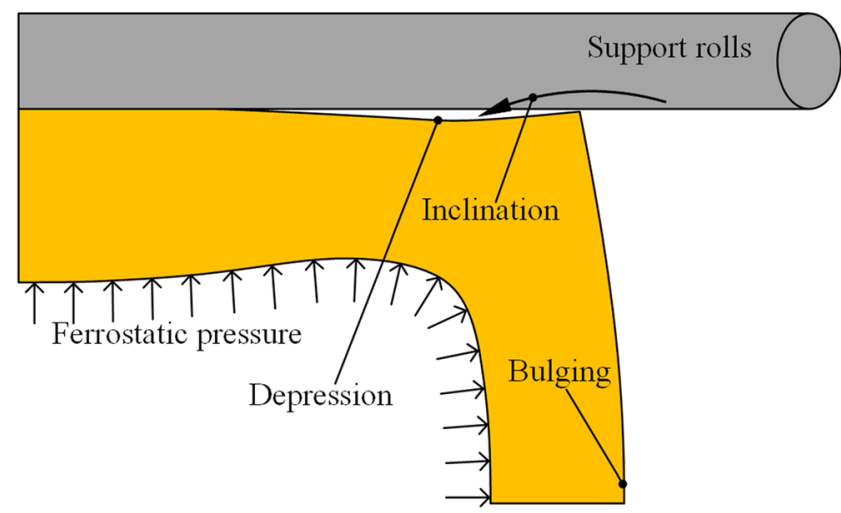

(c)

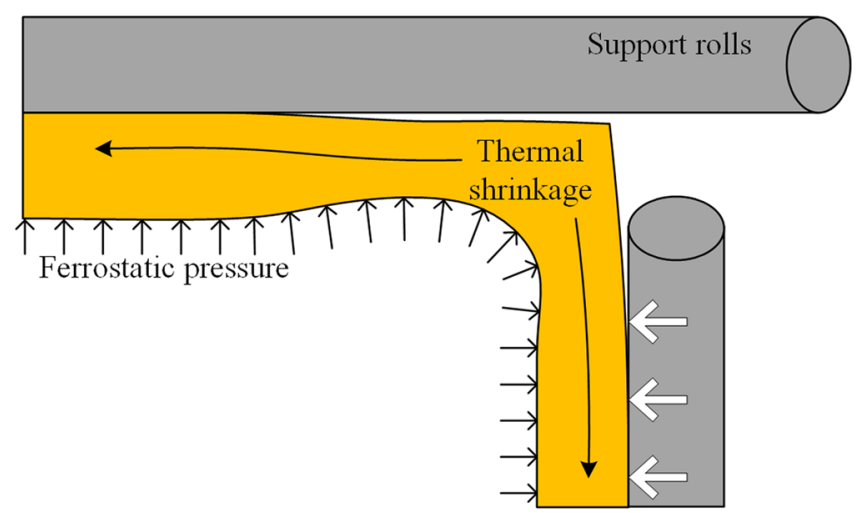

(b)

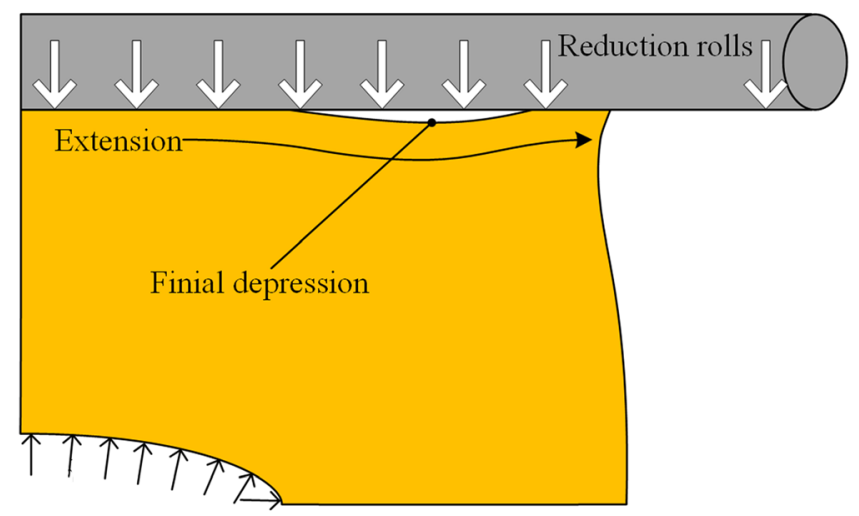

(d)

Fig. 19-Formation and evolution of the longitudinal depression in the (a) mold region, $(b)$ foot roll segment, $(c)$ zones 2 to 4 , and $(d)$ reduction segments.

longitudinal off-corner depression in the mold. Nevertheless, the large interfacial gap in the corner and off-corner areas results in the formation of thin spots at the wide-face off-corner areas, which provides a precondition for the formation of wide-face longitudinal off-corner depressions.

2. The narrow-face bulge has a decisive effect on the formation of consecutive wide-face longitudinal offcorner depression. In the foot roll segment, the support rolls at the narrow face can effectively prevent the solidifying shell from bulging. As a result, no significant longitudinal depression forms in the wide-face off-corner area. Without the narrow-face support in the following segment, the ferrostatic pressure causes the narrow face of the solidifying shell to bulge. Subsequently, the thin spot of the wide-face off-corner area evolves into a longitudinal depression.

3. With the longitudinal depression initially forming at the wide-face off-corner area, a compressive plastic strain occurs in the depression area, and a tensile plastic strain occurs at the solidification front beneath the depression. In zones 2 to 3, the compressive and tensile plastic strains increase significantly with the deepening of longitudinal depression, which may be the main cause of the subsurface cracks accompanying with the longitudinal off-corner depressions.

4. During soft reduction, the wide-face longitudinal off-corner depression is partly flattened by the reduction rolls, and the width and depth of the longitudinal depression are reduced significantly. Compacted by the rolls, the wide face of slab extends in the width direction, meanwhile, an s-shaped curve gradually appears at the narrow face by the end of soft reduction.

\section{ACKNOWLEDGMENTS}

This work was financially supported by the National Natural Science Foundation of China (51774075, 51404061) and Liao Ning Revitalization Talents Program (XLYC1802032). Part of data in this work was supplied by Haiqi Yu, subsidiary of Ansteel Co., Bayuquan 115007, China. 


\section{REFERENCES}

1. S. Wang, B.X. Liu, C.X. Chen, J.H. Feng, and F.X. Yin: J. Alloy. Compd., 2018, vol. 766, pp. 517-26.

2. Y. Wei, L. Gaosheng, and C. Qingwu: J. Mater. Process. Technol., 2015, vol. 217, pp. 317-26.

3. C. Ji, Y. Cui, Z. Zeng, Z. Tian, C. Zhao, and G. Zhu: J. Iron Steel Res. Int., 2015, vol. 22, pp. 53-56.

4. H. Cui, K. Zhang, Z. Wang, B. Chen, B. Liu, J. Qing, and Z. Li: Metals, 2019, vol. 9.

5. Y. Lu, Q. Wang, Y. Li, and S. He: Continuous Casting, 2011, vol. 2011, pp. 33-37.

6. J.K. Brimacombe, E.B. Hawbolt, and F. Weinberg: Can. Metall. Quart., 1980, vol. 19, pp. 215-27.

7. S. Pelak, R. Misicko, D. Fedáková, and J. Bidulská: Mater. Eng., 2009, vol. 16, pp. 21-28.

8. M.L.S. Zappulla and B.G. Thomas: Materials Science Forum, 2018, vol. 941, pp. 112-17.

9. E. Wang, Z. Yang, H. Chen, and B. Ning: J. Northeast. Univ., 1996, vol. 4, pp. 384-87.

10. A. Badri, T.T. Natarajan, C.C. Snyder, K.D. Powers, F.J. Mannion, M. Byrne, and A.W. Cramb: Metall. Mater. Trans. B, 2005, vol. 36, pp. 373-83.

11. T. Matsumiya: ISIJ Int., 2006, vol. 46, pp. 1800-04.

12. Y. Li, H. Li, P. Lan, H. Tang, and J. Zhang: J. Iron Steel Res. Int., 2017, vol. 24, pp. 1159-68.

13. J.K. Brimacombe, F. Weinberg, and E.B. Hawbolt: Metall. Trans. $B, 1979$, vol. 10, pp. 279-92.

14. W.R. Storkman, and B.G. Thomas: Modeling of Casting and Welding Processes, Palm Coast, FL, 1988, Minerals, Metals \& Materials Soc., Warrendale, PA, 1988, pp. 287-97.

15. R.B. Mahapatra, J.K. Brimacombe, and I.V. Samarasekera: Metall. Mater. Trans. B, 1991, vol. 22, pp. 875-88.

16. M.L.S. Zappulla, and B.G. Thomas: TMS 2017 146th Annual Meeting \& Exhibition Supplemental Proceedings, San Diego, CA, 2017, Springer Nature, Cham 2017, pp. 501-10.

17. M.L.S. Zappulla: Mechanisms of Longitudinal Depression Formation in Steel Continuous Casting, Ph.D. Thesis, Colorado School of Mines, Ann Arbor, WC, 2020.
18. M.L.S. Zappulla, and B.G. Thomas: Modelling of Casting, Welding and Advanced Solidification Processes, Jonkoping Sweden, 2020, IOP Publishing, Bristol 2020.

19. C. Li and B.G. Thomas: Metall. Mater. Trans. B, 2004, vol. 35, pp. 1151-72.

20. B.G. Thomas, A. Moitra, and H. Zhu: Proceedings of the 1995 7th Conference on Modeling of Casting, Welding and Advanced Solidification Processes, London, 1995, pp. 241-48.

21. B.G. Thomas, A. Moitra, and R. McDavid: ISS Trans., 1996, vol. 23, pp. 57-70.

22. Z. Cai and M. Zhu: Acta Metall. Sin, 2011, vol. 47, pp. 671-77.

23. X. Liu and M. Zhu: ISIJ Int., 2006, vol. 46, pp. 1652-59.

24. Z. Niu, Z. Cai, and M. Zhu: ISIJ Int., 2019, vol. 59, pp. 283-92.

25. Z. Niu, Z. Cai, and M. Zhu: Ironmak. Steelmak., 2020, vol. 47, pp. $1135-47$

26. C. $\mathrm{Wu}, \mathrm{C}$. Ji, and M. Zhu: Steel Res. Int., 2017, vol. 88, p. 1600514

27. M.S.C. Marc: Theory and user information, MSC Software Corporation, Newport Beach, 2016.

28. T. Nozaki, J. Matsuno, K. Murata, H. Ooi, and M. Kodama: Trans. ISIJ, 1978, vol. 18, pp. 330-38.

29. G. Xia and A. Schiefermüller: Steel Res. Int., 2010, vol. 81, pp. $652-59$.

30. P.F. Kozlowski, B.G. Thomas, J.A. Azzi, and H. Wang: Mater. Trans. A, 1992, vol. 23, pp. 903-18.

31. K. Liu, Y. Chang, Z. Han, and J. Zhang: J. Iron Steel Res. Int., 2013, vol. 20, pp. 38-47.

32. H. Mizukami, K. Murakami, and Y. Miyashita: Tetsu-to-Hagane, 1977, vol. 63, p. 652.

33. M. Uehara, I.V. Samarasekera, and J.K. Brimacombe: Ironmak. Steelmak., 1986, vol. 13, pp. 138-53.

34. M.B. Santillana: Thermo-mechanical properties and cracking during solidification of thin slab cast steel, Ph.D. Thesis, Delft University of Technology, Delft, Holland, 2013.

35. R. Dippenaar, S. Moon, and E.S. Szekeres: Iron Steel Technol., 2007, vol. 4, pp. 105-15.

Publisher's Note Springer Nature remains neutral with regard to jurisdictional claims in published maps and institutional affiliations. 